University of Wollongong

Research Online

Faculty of Engineering and Information

Faculty of Engineering and Information

Sciences - Papers: Part A

Sciences

$1-1-2014$

Characterisation of gas turbine dynamics during frequency excursions in power networks

Lasantha Meegahapola

University of Wollongong, lasantha.meegahapola@rmit.edu.au

Follow this and additional works at: https://ro.uow.edu.au/eispapers

Part of the Engineering Commons, and the Science and Technology Studies Commons

Research Online is the open access institutional repository for the University of Wollongong. For further information contact the UOW Library: research-pubs@uow.edu.au 


\title{
Characterisation of gas turbine dynamics during frequency excursions in power networks
}

\begin{abstract}
Gas turbines inherently depict unique frequency response characteristics compared with other conventional synchronous generation technologies as their active power output is not entirely determined by the governor response during frequency deviations of the power network. Thus, gas turbine dynamics significantly influence on system stability during frequency events in power networks. Power system and power plant operators require improved understanding of the gas turbine characteristics during various frequency events in order to mitigate adverse impact on power system. Therefore a comparative analysis has been performed between combined-cycle gas turbines (CCGTs) and open-cycle gas turbines (OCGTs) in order to characterise the dynamic behaviour considering different types of frequency events in power networks. Study has shown that CCGTs result in significant frequency variations in power networks in comparison with OCGTs because of the temperature control action performed by the fast acting inlet guide vanes at the combustor. In particular, they are susceptible to lean blowout during large frequency increase events such as short-circuit faults in power networks. Furthermore, a case study was developed based on the New England-39 bus system in order to illustrate the impact of gas turbine dynamics on network frequency during short-circuit events in power networks.
\end{abstract}

\section{Keywords}

Combined-cycle gas turbine (CCGT), frequency excursions, lean blowout (LBO), inlet guide vanes (IGV), open-cycle gas turbine (OCGT)

\section{Disciplines}

Engineering | Science and Technology Studies

\section{Publication Details}

L. Meegahapola, "Characterisation of gas turbine dynamics during frequency excursions in power networks," IET Generation, Transmission and Distribution, vol. 8, (10) pp. 1733-1743, 2014. 


\title{
Characterisation of Gas Turbine Dynamics during Frequency Excursions in Power Networks
}

\author{
Lasantha Meegahapola1+ \\ ${ }^{1}$ School of Electrical, Computer and Telecommunications Engineering, \\ University of Wollongong, Wollongong, 2500, Australia.
}

\section{Abstract}

Gas turbines inherently depict unique frequency response characteristics compared to other conventional synchronous generation technologies as their active power output is not entirely determined by the governor response during frequency deviations of the power network. Thus, gas turbine dynamics significantly influence on system stability during frequency events in power networks. Power system and power plant operators require improved understanding of the gas turbine characteristics during various frequency events in order to mitigate adverse impact on power system. Therefore, a comparative analysis has been performed between combined-cycle gas turbines (CCGTs) and open-cycle gas turbines (OCGTs) in order to characterise the dynamic behaviour considering different types of frequency events in power networks. Study has shown that CCGTs result in significant frequency variations in power networks in comparison to OCGTs due to the temperature control action performed by the fast acting inlet guide vanes (IGV) at the combustor. In particular, they are susceptible to lean-blowout (LBO) during large frequency increase events such as short-circuit faults in power networks. Furthermore, a case study was developed based on the New England-39 bus system in order to illustrate the impact of gas turbine dynamics on network frequency during short-circuit events in power networks.

Keywords: Combined-cycle gas turbine (CCGT), frequency excursions, lean blowout (LBO), inlet guide vanes (IGV), open-cycle gas turbine (OCGT). 


\section{Introduction}

During the last three decades combined-cycle gas turbines (CCGTs) have received immense industry attention as one of the economically viable and environmentally friendly thermal power generation technology due to their high efficiency, flexibility and low green-house gas emission. Renewable power generators have widely been integrated to thermal power networks due to increased pressure to reduce green-house gas emissions from power generation [1]. However, high variability and intermittency of nonconventional renewable power generators (i.e. wind and solar power generation) have resulted in challenging issues during system operation. Consequently, the open-cycle gas turbines (OCGTs) became a viable fast-start generation technology to cope with the variability in wind power generation. Therefore, many power networks operating with a significant penetration of renewable power generation have deployed OCGTs to effectively manage the renewable power variability during system operation (e.g. Ireland, and South Australia).

A number of studies have been conducted on gas turbine modelling for dynamic and stability studies [2-6]. The work presented by Rowen [2] was one of the pioneering studies in the early literature, and subsequently that model was further improved by including variable inlet-guide-vanes (IGVs) to control air-flow to the combustion chamber. The IEEE working group has presented a dynamic model for a single-shaft, constant-speed gas turbine with IGVs while considering the physical thermodynamic properties and laws [3]. In [4-5], authors have placed a special emphasis on modelling gas turbines for system frequency excursions, and developed a physical model to accurately determine the gas turbine power output during various frequency excursions. The CIGRE working group has also developed a gas turbine model for power system dynamic studies based on the Rowen's model; however turbine dynamics were represented by a second-order block in contrast to the mathematical function in the Rowen's model for the torque calculation [6]. Moreover, a gas turbine dynamic model comparison, parameter estimation and validation procedures are presented in [7-9]. 
The dynamic response characteristics of gas turbines during frequency decrease events are well established in the published literature [10-12]. During frequency decrease events gas turbine (both the CCGT and OCGT) power output decreases due to the reduction in pressure ratio across the gas turbine. This occurs due to the reduction in airflow to the combustion chamber as the grid synchronised compressor slows down during the low frequency event. In addition, dynamics associated with the temperature control scheme of the CCGT also lead to further reduction in the CCGT power output during low frequency events by reducing the fuel flow to the combustion chamber. Various system operators have set operational guidelines to alleviate such adverse impact from CCGTs during low frequency events in power networks [13]. However, less attention has been placed on gas turbine dynamics during frequency increase events in power networks, in particular, during sustained short-circuit faults (i.e. long duration faults which are not cleared either by primary or backup protection).

During the short-circuit event, network voltage decreases significantly, and subsequently that voltage drop will result in a power imbalance between the electrical power output and mechanical power input to the generator due to the voltage drop at the generator terminal. As the electrical power output is lower than the mechanical power input, it will create an acceleration torque at the generator, hence the local frequency will increase. This is due to the fact that rotor speed is directly coupled to the speed of the rotating magnetic field of the air-gap, hence any rotor speed deviation will result in frequency variations in the rotating magnetic field, hence the frequency of the generated voltage waveform. Furthermore, as the electromechanical torque attempts to adjust with the mechanical torque input it ultimately creates rotor speed oscillations, hence create local frequency oscillations [14]. Consequently, gas turbine governor responds to these frequency oscillations, and ultimately leads to detrimental operating conditions at the CCGT plant. Furthermore, depending on the severity of the ROCOF, it may lead to leanblowout (LBO) and may result in complete plant shut down as occurred in the Florida blackout [15-16]. Similar over-frequency events can be resulted from tripping of a large load or disconnection of an interconnector when exporting power to another region, 
however, rate-of-change-of-frequency (ROCOF) is much lower compared to short-circuit events and does not lead to large electromechanical oscillations at the generator. Therefore, power utility engineers require an in-depth understanding of the associated gas turbine dynamics during frequency increase events.

The main objective of this paper is to investigate gas turbine dynamics during various frequency events in power networks, and present a comparative analysis between the CCGT and OCGT plants. This paper is organised as follows: The gas turbine modelling descriptions are outlined in Section 2. The test system description and characteristics of various types of faults are discussed in Section 3. The dynamic behaviour of the CCGT and OCGT during frequency events are presented in Section 4. A case study based on the New England-39 bus system is presented in Section 5. The study conclusions are summarised in Section 6. 


\section{Gas Turbine Modelling}

This section outlines the modelling descriptions of the CCGT, OCGT and exciter model used for dynamic simulations. All the models were developed in the DIgSILENT Power Factory using the dynamic simulation language (DSL).

\subsection{The CCGT Dynamic Simulation Model}

A CCGT plant is comprised of a gas turbine and a steam turbine unit, while the exhaust gases from the gas turbine are extracted to generate steam for the steam turbine (ST) unit. A schematic diagram of the CCGT plant is illustrated in Figure 1.

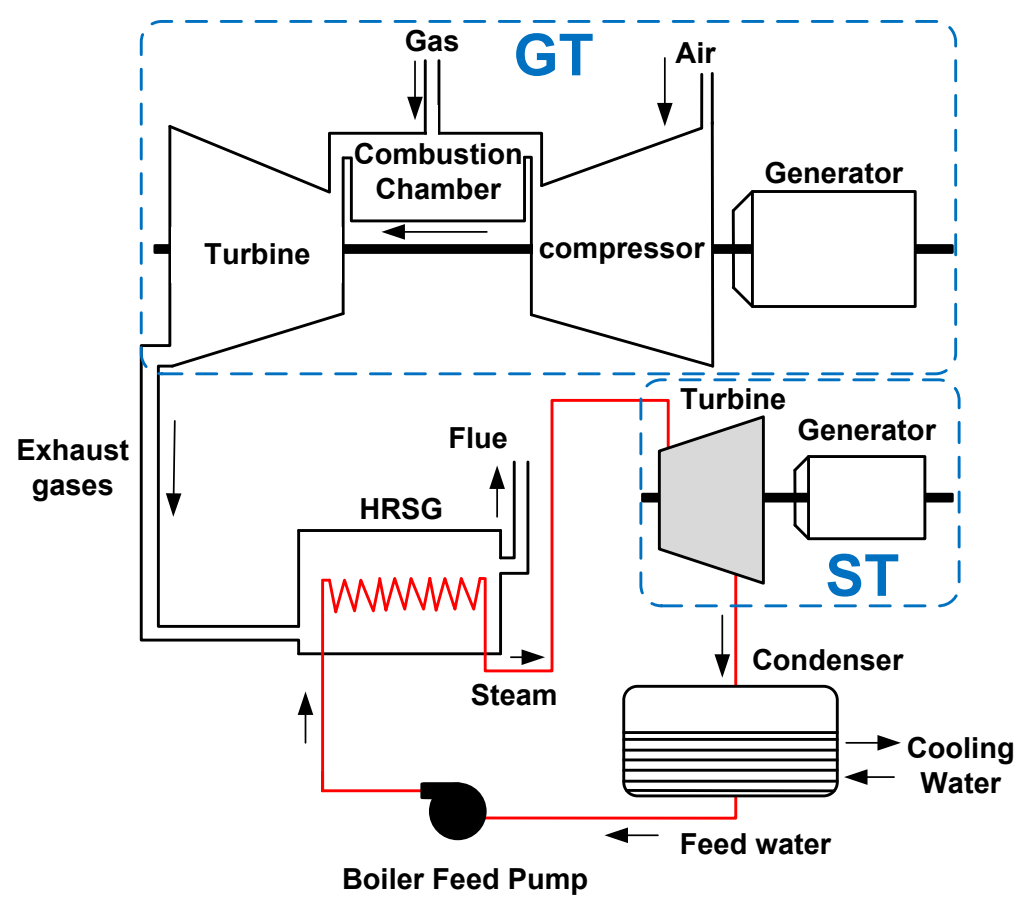

Figure 1: The layout the CCGT plant.

According to the published literature various modelling conceptions have been used by various researchers to model CCGTs for power system dynamic studies. For example, in the IEEE model, physical thermodynamic properties/laws associated with the turbine and combustor, and control loops (i.e. temperature control, airflow control and fuel control) are used to represent the dynamics of the CCGT plant [3]. However, in contrast to the IEEE model, the Rowen's model uses mathematical functions to represent dynamics associated with the turbine and combustor [2]. The accuracy of the Rowen's model to evaluate frequency response has been thoroughly verified in [10-12]. 
The work presented in this paper is mainly based on the Rowen's CCGT model presented in [10] for frequency dynamic studies. A schematic diagram of the CCGT model developed in the DIgSILENT Power Factory is shown in Figure 2. It should be noted that the parameter values are based on $[2,10]$ and are given in the Appendix A.

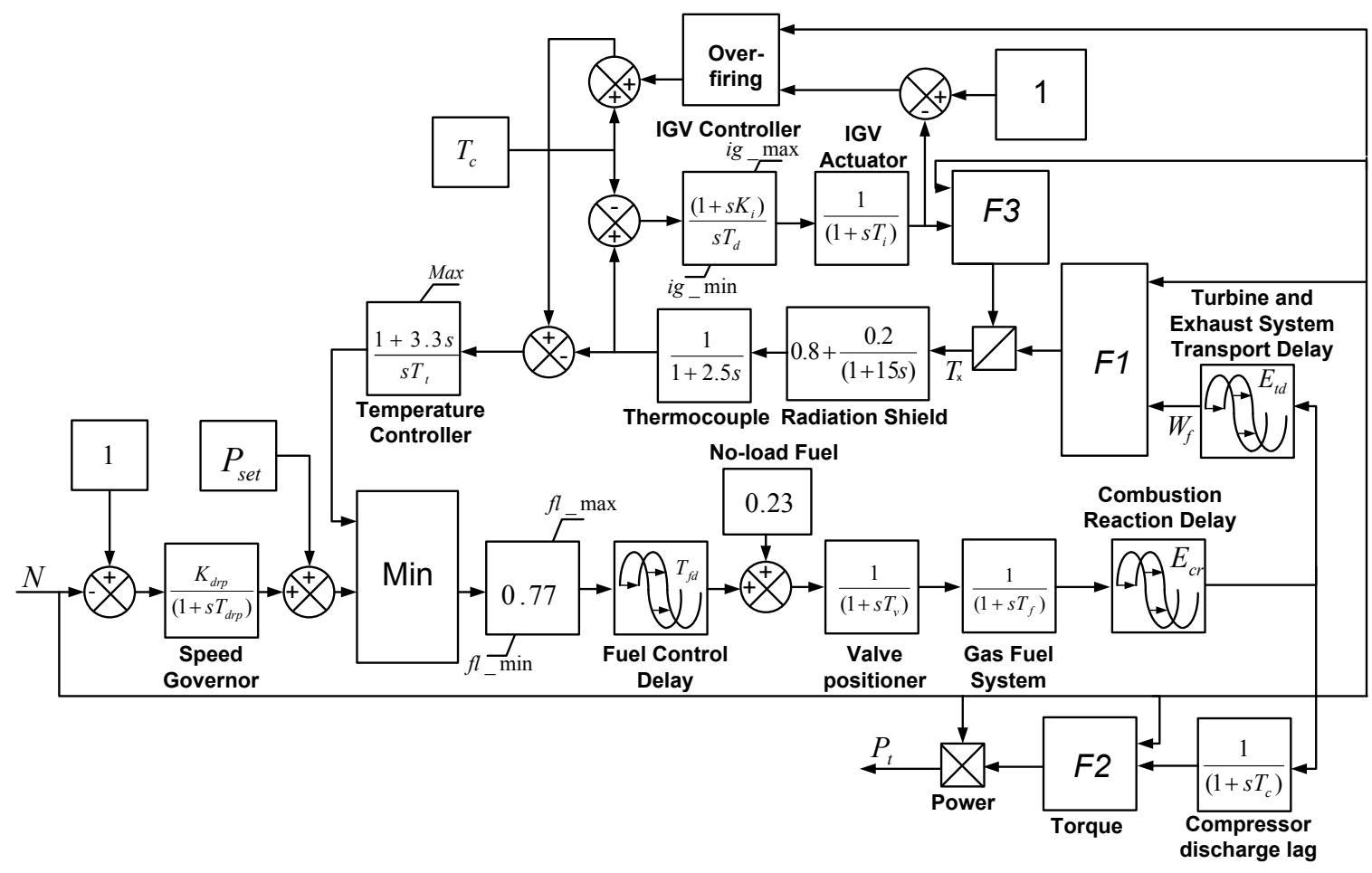

Figure 2: CCGT model developed in DIgSILENT Power Factory.

The CCGT model is comprised of two main control loops (i.e. speed control loop (fuel control) and temperature control loop (air-flow control)). At the speed control loop, generator shaft-speed error is feed into the speed-governor which determines the fuel adjustment required to correct the speed deviation. The output of the speed governor is proportional to the speed error, since it operates with a droop [2]. Then load reference set-point $\left(P_{\text {set }}\right)$ is added to the speed-governor response to determine the combined fuel requirement (see Figure 2). However, if the gas turbine is operating with an isochronous governor, then speed error is fed through a proportional-integral (PI) controller, in which corrective action is carried out until the speed error becomes zero and generator reaches its rated power capability. Therefore, $P_{\text {set }}$ is zero when the gas turbine operates with an isochronous governor [2]. The minimum signal between governor control loop and speed control loop is selected, and then no-load fuel requirement is added to determine the final fuel requirement for the combustor after accounting for the delays associated the 
fuel system. After combustion process the gases will be expanded at the turbine in number of stages while generating the driving torque for the generator. Following this the CCGT turbine exhaust temperature is determined based on function $F 1$ as follows:

$F 1=(1 /[1+0.005 \times(15-T a)]) \times\left\{\begin{array}{l}{\left[\operatorname{Tr}-453 \times\left(N^{2}-4.21 N+4.42\right) \times 0.82 \times\left(1-W_{f}\right)\right]} \\ +722 \times(1-N)+1.94 \times(\operatorname{MaxIGV}-I G V)\end{array}\right\}$

where, $T_{a}, T_{r}, N$, and $W_{f}$ denote the ambient temperature, rated turbine exhaust temperature, generator shaft-speed and exhaust gas flow respectively. MaxIGV denote the maximum angle of the inlet guide vanes (IGVs) while IGV refers to the current IGV angle. The turbine torque is calculated using the following function:

$F 2=1.3 \times\left(W_{f}-0.23\right)+0.5 \times(1-N)$

In order to maintain the exhaust temperature at the optimal value to achieve the highest efficiency, CCGTs are equipped with variable inlet guide vanes (IGVs). Therefore, the turbine exhaust temperature is further modified based on the IGV position. The airflow correction, based on the IGV position, is determined by the following function:

$F 3=N \times[519 /(T a+460)] \times(\operatorname{Ligv})^{0.257}$

$L_{i g v}$ refers to the inlet guide vane current position. By changing the IGV position it changes the incidence angle at the inlet of the impeller, hence the IGV angle (IGV) corresponds to the incidence angle. It should be further noted that CCGTs are equipped with an over firing capability.

Response of the heat recovery steam generator (HRSG) depends on gas turbine exhaust flow $\left(W_{f}\right)$ and exhaust gas temperature $\left(T_{x}\right)$. A schematic of the steam turbine model is shown in Figure 3.

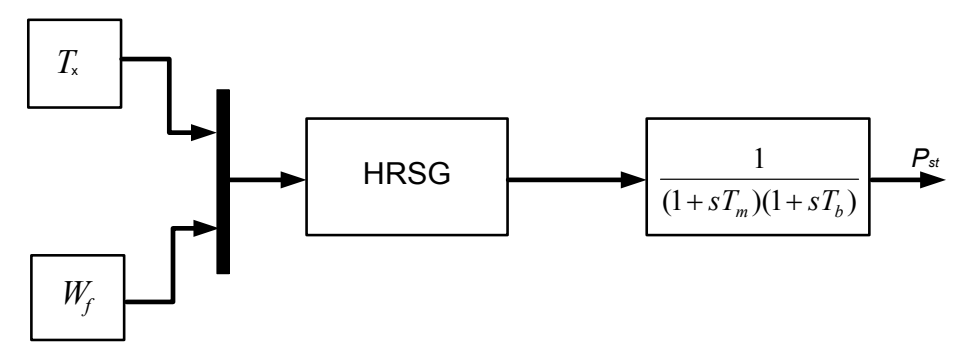

Figure 3: Steam turbine model. 
The mechanical power output of the steam turbine depends on the gas turbine exhaust energy, and two time lags associated with the high pressure and low pressure sections of the steam turbine. These time lags correspond to the tube metal heat capacitance (order of $5 \mathrm{~s}$ ) and the boiler storage time constant (order of 50 to $100 \mathrm{~s}$ ). Therefore, due to the large time constants associated with the steam turbine it has a very insignificant effect on overall plant response during the study period (10 s). Furthermore, as the steam turbine generator is typically operated at the sliding pressure mode it can't provide any primary response. Therefore, heat recovery steam generator (HRSG) and steam turbine were not considered in this study.

\subsection{The OCGT Dynamic Simulation Model}

Typically, the exhaust temperature of the OCGT is not controlled at an optimal value, since a heat recovery mechanism is not used during the open-cycle operation. Therefore, variable IGVs are not utilised in OCGTs. A schematic diagram of the OCGT model developed in the DIgSILENT Power Factory is shown in Figure 4.

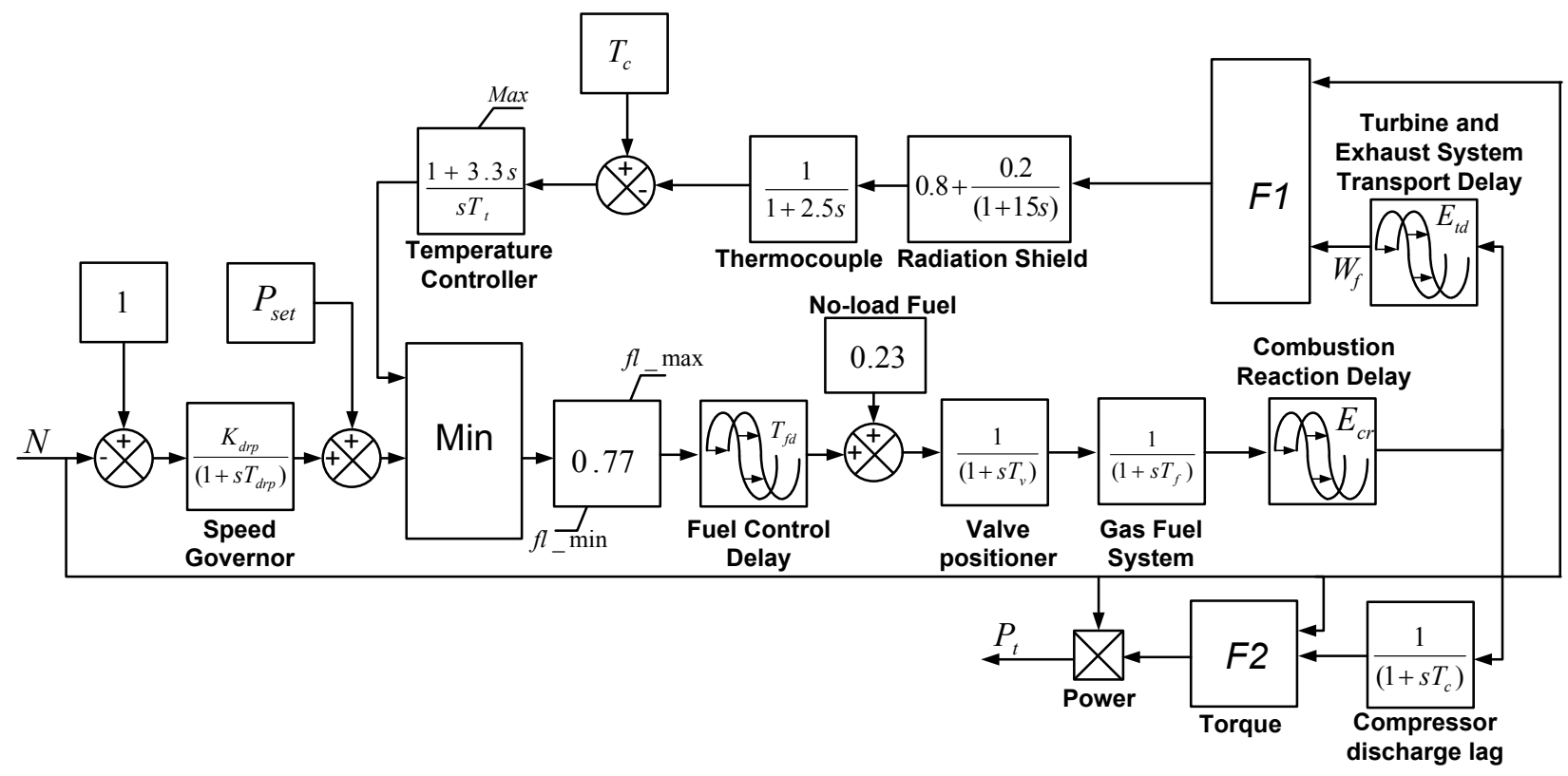

Figure 4: OCGT model developed in DIgSILENT Power Factory.

Since OCGTs don't have variable IGVs the exhaust temperature is calculated using the following function:

$F_{1}^{\prime}=\operatorname{Tr}-700\left(1-W_{f}\right)+550(1-N)$ 
However, the OCGT turbine power output is mainly determined by F2. Furthermore, the acceleration control loop was not included for the CCGT and OCGT models, since it is only active during gas turbine start up. Both the CCGT and OCGT are assumed to utilise the same internal parameters for the speed control, and temperature control loops, although the presence of IGVs and an over firing capability distinguish the models from each other. This allows the OCGT to vary its exhaust temperature based on power output of the generator. The fuel demand for both CCGT and OCGT is determined based on the lowest signal between governor control loop and temperature control loop. A governor droop of $4 \%$ was assumed for both the CCGT and OCGT. The CCGT and the OCGT temperature control system was designed based on Fahrenheit.

\subsection{Excitation System Model}

The generator model of both the CCGT and OCGT is equipped with the IEEE Type-1 exciter model [17]. A schematic diagram of the excitation system is shown in Figure 5, and parameter values are presented in the Appendix B.

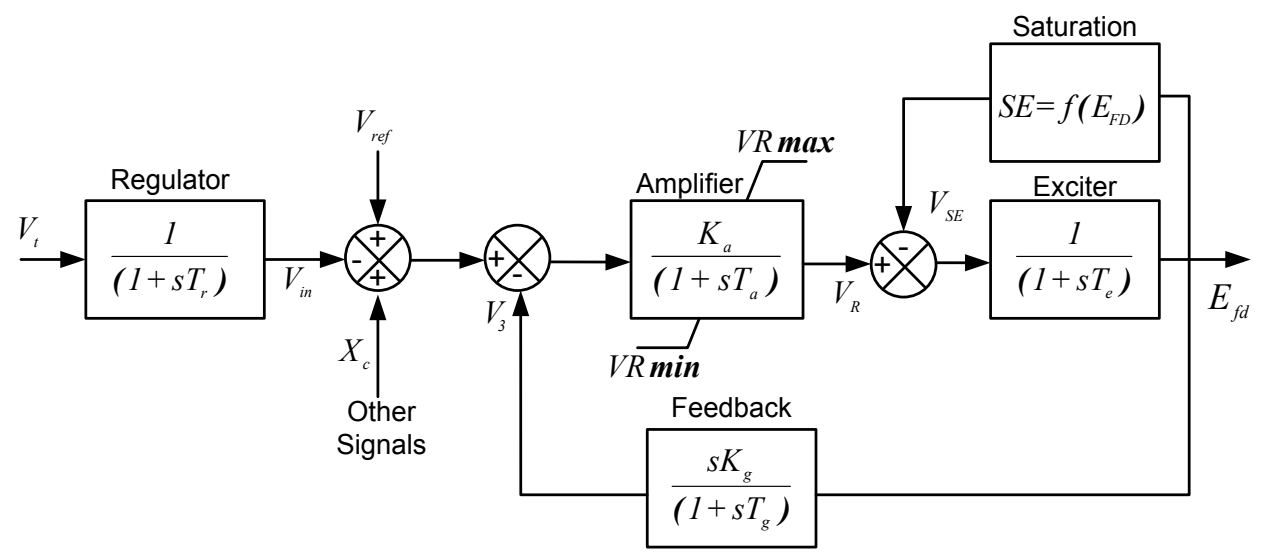

Figure 5: IEEE-Type 1 exciter model. [17]

The IEEE Type 1 is a brushless excitation system where generator terminal voltage $\left(V_{t}\right)$ is filtered first at the regulator and compared with the reference voltage $\left(V_{\text {ref }}\right)$ to generate the error voltage. At the second summing point error input is compared with the excitation damping loop signal and feed into the main regulator. Following this, the maximum and minimum limits of the regulator are imposed so that regulator output will not exceed practical limits. Then exciter saturation effects are incorporated prior to deciding the generator field voltage $\left(E_{f d}\right)$. 


\section{Classification of Frequency Events and Test Network System}

Electricity networks are exposed to various disturbances and consequently it will affect system frequency. Based on the characteristics of frequency variations they can be mainly classified into three types:

a) Load increase/generator outage (Frequency decrease)

b) Load reduction (Frequency increase)

c) Three-phase short-circuit faults (Frequency oscillations)

The frequency traces illustrated in Figure 6 are derived using an actual power network with majority of the generation is comprised of gas turbine units [14].

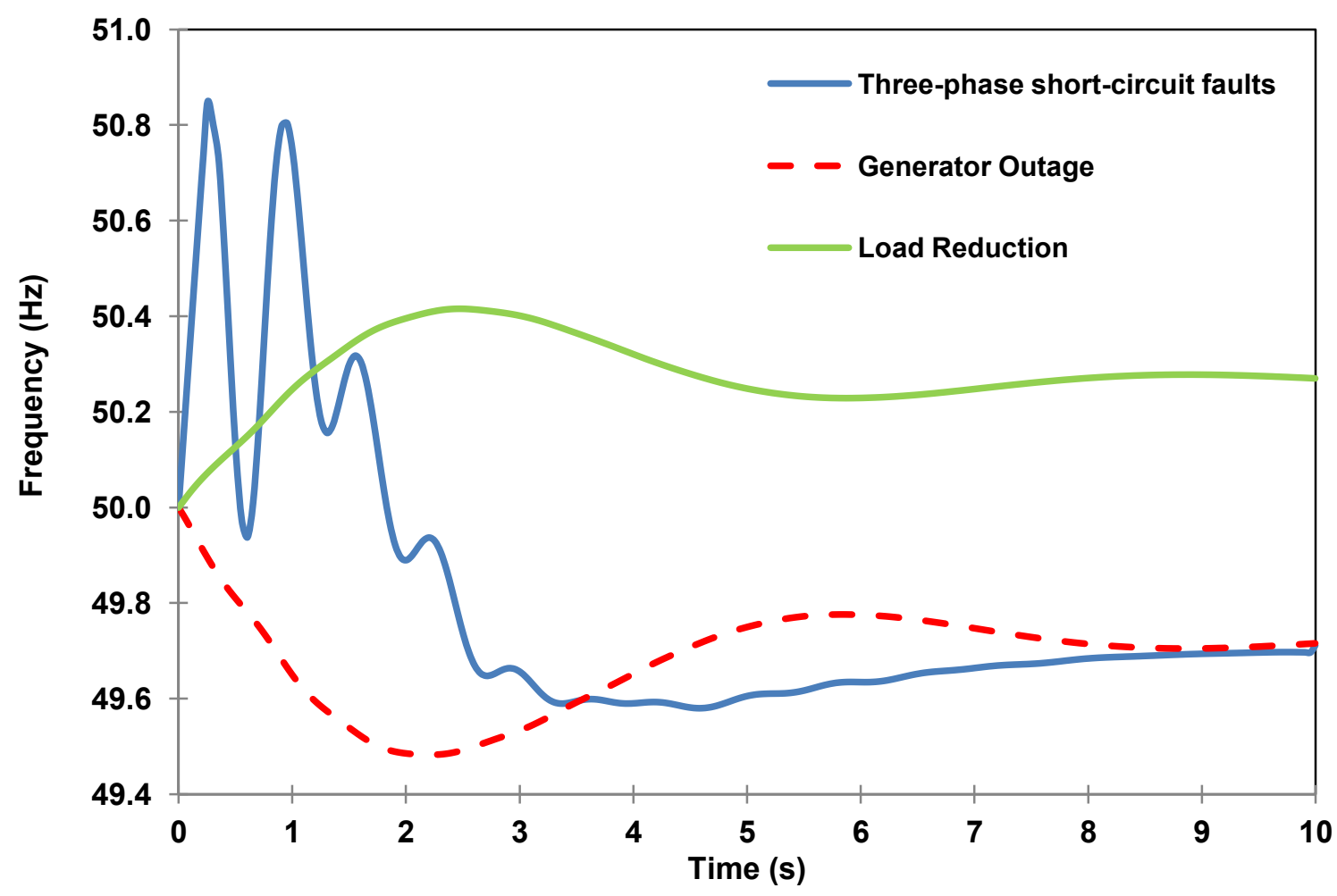

Figure 6: Frequency variations during different system events.

According to Figure 6, each event has resulted in different frequency variations. In particular, during transient short-circuit faults; a large ROCOF can be observed which is detrimental for gas turbines. As shown in Figure 6, during the short-circuit event, it indicates a frequency increase of $0.85 \mathrm{~Hz}$ within $250 \mathrm{~ms}$ while indicating a ROCOF of $3.4 \mathrm{~Hz} / \mathrm{s}$. However, generator outage events and load reduction events cause slow and gradual frequency variations compared to short-circuit events in power networks. 


\subsection{The Test Network}

A single machine test network was developed in order to investigate the frequency response characteristics of the CCGT and the OCGT. The test system is comprised of a 2000 MW load which is represented by a constant impedance load model. The system equivalent was represented by an external grid model in the DIgSILENT Power Factory. System equivalent has an inertia constant $(\mathrm{H})$ of $6 \mathrm{~s}$ and short-circuit capacity (SCC) of 5000 MVA. In addition, a frequency droop of $4 \%$ was chosen for the system equivalent. A schematic of the test system model is shown in Figure 7.

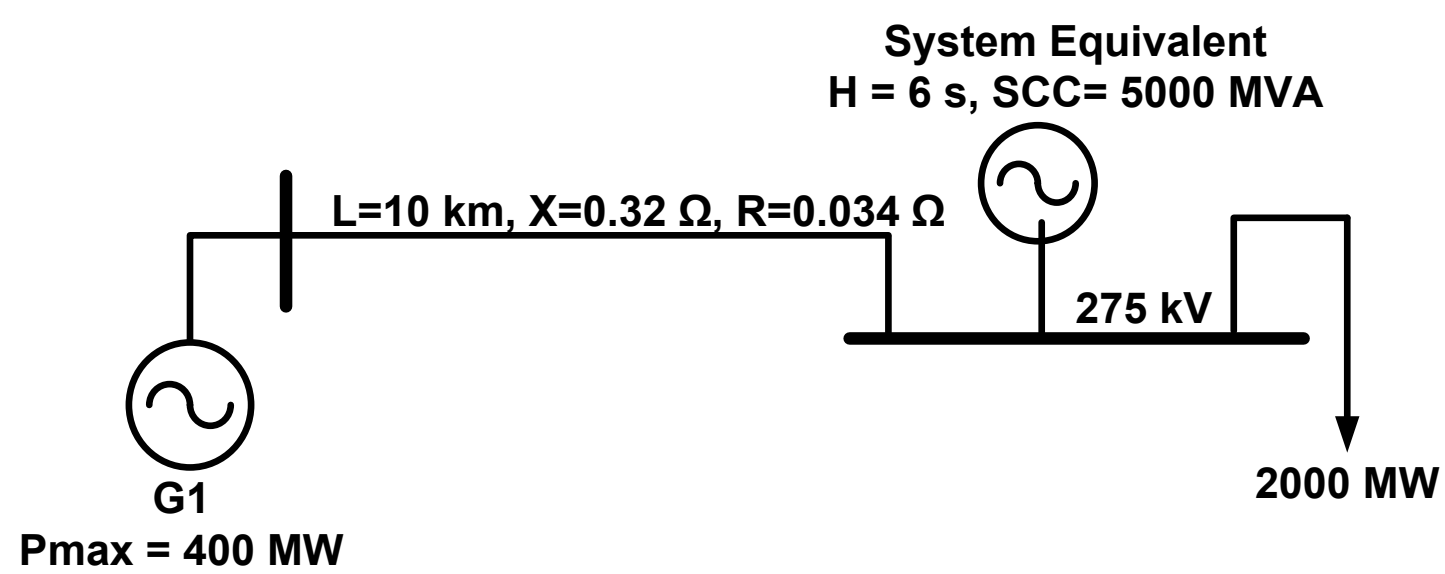

Figure 7: Test system model.

The investigation was carried out separately for both the CCGT and OCGT models in order to avoid any dynamic interactions between the CCGT and the OCGT; hence the plant model of the generator G1 (see Figure 7) was represented by either CCGT or OCGT model. Furthermore, it is assumed that G1 is operating at zero reactive power output. It is assumed that the CCGT has an inertial constant of $8 \mathrm{~s}$ and a rated active power output of $400 \mathrm{MW}$, while the OCGT has an inertial constant of $4 \mathrm{~s}$ and a rated active power output of $200 \mathrm{MW}$. The CCGT was rated 500 MVA and the OCGT was rated at 250 MVA. Moreover, it should be noted that in order to obtain same active power output from the OCGT, two units were operated in parallel to obtain same rated power output as the CCGT. Both the CCGT and OCGT capability characteristics were determined based on the transmission system operator (TSO) specifications [18, 19]. 


\section{Gas Turbine Dynamics during Frequency Events}

\subsection{Frequency Decrease Event (Network Load Increase)}

A frequency decrease event was simulated at $1 \mathrm{~s}$ by connecting a $200 \mathrm{MW}$ load to the test network in Figure 7, and it is assumed that prior to this event the test system was operating with a $1800 \mathrm{MW}$ load. Separate tests have been carried out for both the CCGT and OCGT, and it is assumed that they are operating at rated power output (i.e. 400 MW) prior to the disturbance. Figure 8 illustrates the CCGT and OCGT response following a frequency reduction event in the network. The following per-unit conventions were used for the traces shown in Figure 8. The per unit fuel demand was defined based on the fuel demand required for the rated power output (i.e. $400 \mathrm{MW}$ ). The per-unit turbine power output was defined based on the rated power output of the generator.

When the 200 MW load was connected to the network ( $t=1 \mathrm{~s}$ ), during initial few seconds system frequency decreases at a faster rate when the OCGT is in place, in comparison to the CCGT. This is due to the fact that CCGT has much larger inertia in comparison to the OCGT, hence the CCGT indicates much larger inertial response than the OCGT (see Figure 8). It should be noted that system frequency variation is based on the instantaneous power balance in the network region, and also it is reflected as average generator shaft-speed variation. However they may be some transient shaftspeed variations at the generator during system frequency variations due to the instantaneous power imbalance at the generator and rotor angle variations. Furthermore, inertial response is greater than the rated active power output of both machines (400 MW), however it is within the generator stator current limit as the generator is rated at 500 MVA.

As the system frequency decreases, the turbine power output of both the CCGT and OCGT also decreases and that phenomenon can be explained as follows: When the system frequency decreases, the compressor slows down while reducing the air-flow to the combustion chamber, and that will reduce the pressure ratio across the turbine. Subsequently, turbine power output is reduced as no longer fuel input to the combustion 
chamber can be increased by the governor signal as the generator is operating at its rated power output (i.e. maximum fuel limit has reached). However, this reduction is $0.008 \mathrm{pu}$ which is negligibly small in comparison to the turbine power reduction (which occurs at $6.8 \mathrm{~s}$ ). Subsequently, after few seconds system frequency decreases to 49.18 Hz for the CCGT case, while the corresponding minimum frequency nadir for the OCGT was $49.22 \mathrm{~Hz}$. This phenomenon can be explained as follows:

When system frequency decreases, the compressor slows down while reducing the air flow to the combustion chamber, and subsequently exhaust gas temperature will increase due to the increase in the fuel-to-air ratio at the combustion chamber. As mentioned earlier, CCGTs are equipped with variable IGVs, since they must maintain an optimal exhaust temperature in order to achieve maximum efficiency at the heat recovery stage (i.e. through the heat recovery steam generator (HRSG)). Therefore, the exhaust temperature is corrected by altering IGVs. Conversely, OCGTs don't incorporate variable IGVs as they operate at the open-cycle mode. When the CCGT is operating at rated power output its IGVs are now fully open, hence IGVs could not correct the fuel-to-air ratio in the combustion chamber. Therefore, compressor speed is the only determinant of the fuel-to-air ratio, hence the exhaust temperature will increase. Ultimately, the CCGT exhaust gas temperature increases beyond the OCGT exhaust gas temperature when system frequency decreases.

The fuel selector selects the minimum value between the temperature control signal and the speed governor signal in order to determine the fuel demand. The CCGT exhaust temperature increases at a much faster rate than the OCGT, since IGVs can no longer control the CCGT exhaust temperature. Subsequently the CCGT temperature control loop overrides the speed governor signal, ultimately fuel input to the combustion chamber is reduced (reduced from $1 \mathrm{pu}$ to $0.975 \mathrm{pu}$ within $3.5 \mathrm{~s}$ ) while reducing the exhaust gas temperature $(t=6.6 \mathrm{~s})$, consequently turbine power output also reduces below the OCGT power output $(\mathrm{t}=6.8 \mathrm{~s})$. Therefore, the system frequency starts to 
decrease below the OCGT frequency $(t=8.1 \mathrm{~s})$, while worsening the frequency stability issues in the network.

The exhaust temperature spread can be used as the main lean blowout (LBO) signature for the gas turbine, which is measured as the difference between two temperature values within $2 \mathrm{~s}$ time window [15]. The exhaust temperature spread of $19.5^{\circ} \mathrm{F}$ has been indicated by the CCGT while the temperature spread for the OCGT units was $8.63{ }^{\circ} \mathrm{F}$. In both cases the exhaust temperature spread is less than the temperature spread at the LBO condition (i.e. $200^{\circ} \mathrm{F}$ ), hence it's unlikely resulted in a LBO condition at this particular frequency decrease event. 

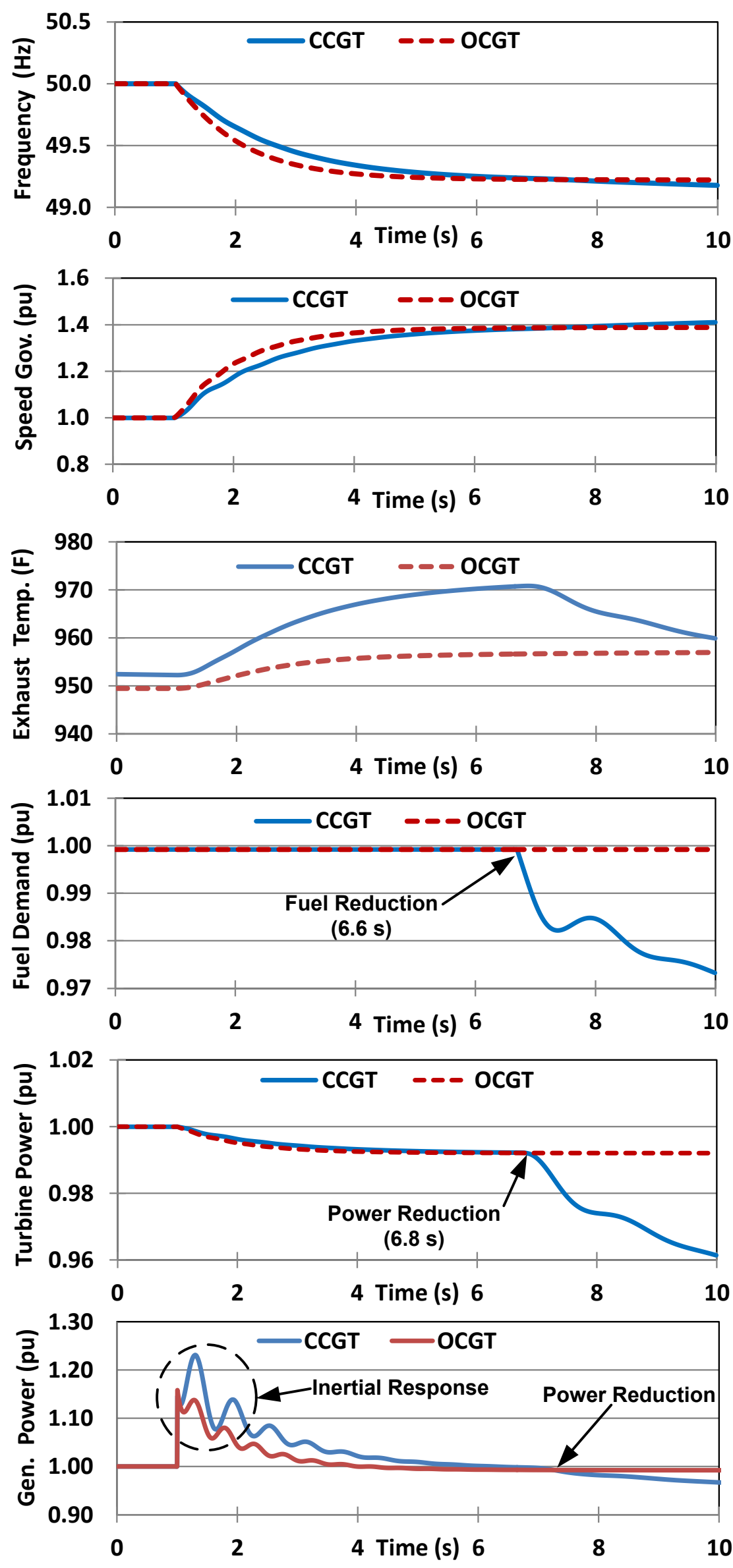

Figure 8: Dynamic response of the CCGT and OCGT during a frequency decrease event. 
The system frequency, gas turbine power output and the exhaust temperature, when the gas turbines are operated below the rated power output (i.e. at $380 \mathrm{MW}$ ) are shown in Figure 9 .
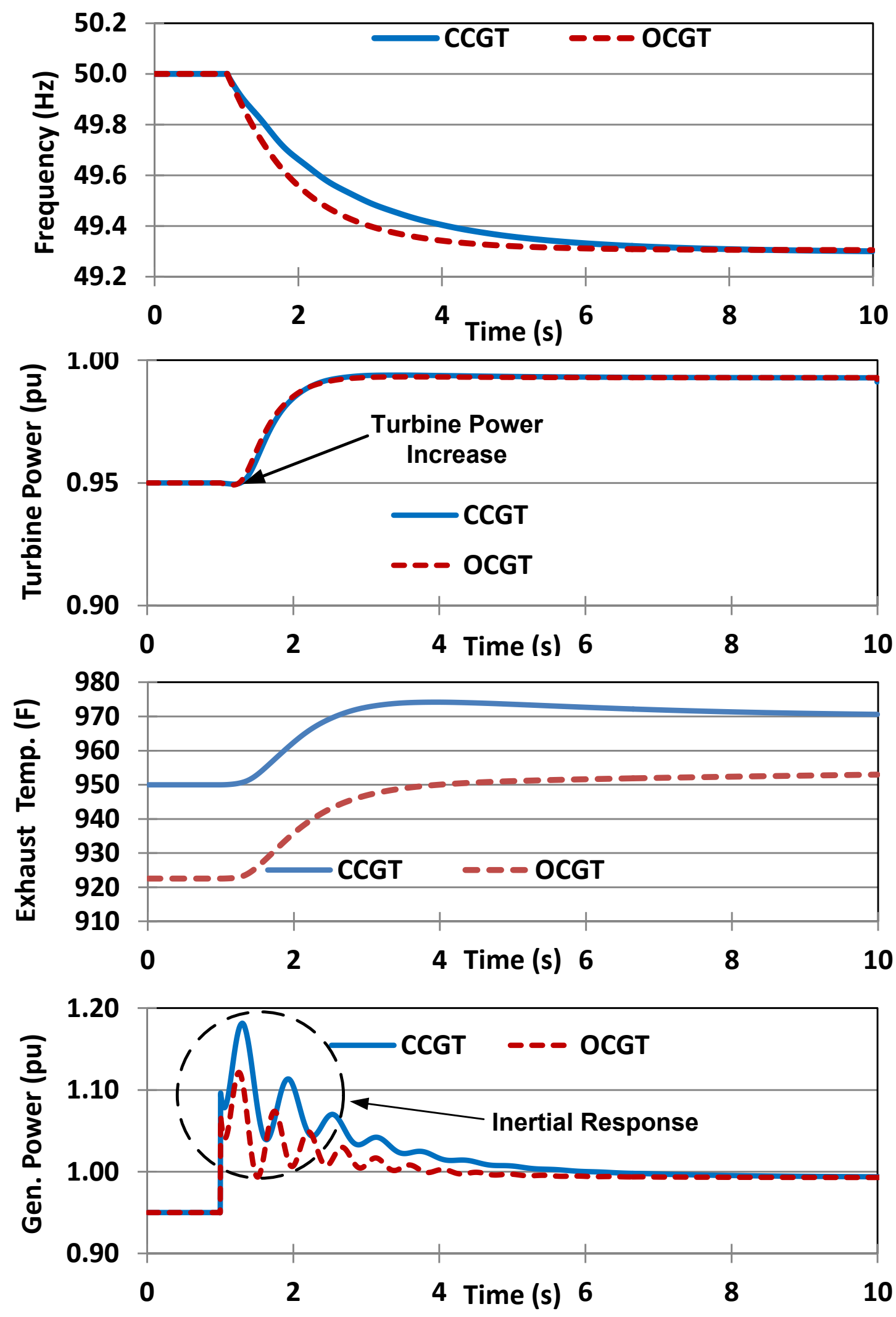

Figure 9: Gas turbine dynamics when operating below rated power output. 
When the CCGT operates below rated power output (i.e. $380 \mathrm{MW}$ ) the exhaust gas temperature doesn't increase rapidly as before, and hence the generator power output increases based on the speed governor response in order to improve the system frequency. Although, the ROCOF for the OCGT scenario is slightly larger than the CCGT scenario both units have indicated the same turbine power output increase.

The OCGT has indicated an exhaust temperature spread of $24.5^{\circ} \mathrm{F}$ while for the CCGT exhaust temperature spread is $30^{\circ} \mathrm{F}$. This is because OCGTs are not operating at an optimal temperature; hence its steady-state exhaust temperature varies with the power output. Thus, it's highly unlikely resulted in a LBO condition when gas turbines are operated below the rated power output.

\subsection{Gas Turbine Dynamic during Frequency Increase Events (Load Reduction)}

A frequency increase event was simulated at $1 \mathrm{~s}$ by disconnecting a $200 \mathrm{MW}$ load in the network, and prior to this event test network was operating with a $2000 \mathrm{MW}$ load. It is assumed that both the CCGT and OCGT are operating at rated power output. Figure 10 illustrates the CCGT and OCGT response following a frequency increase event in the network. 

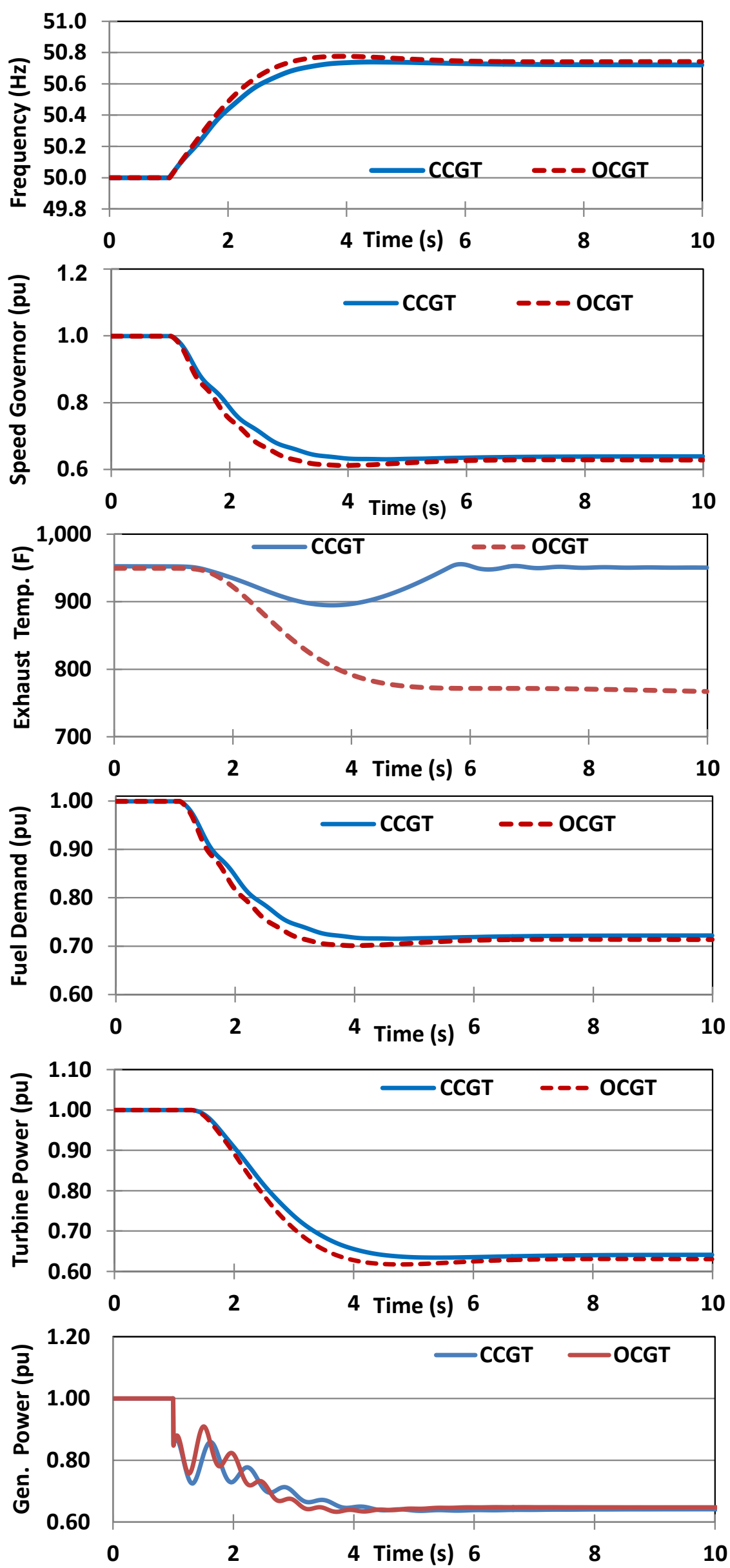

Figure 10: Dynamic response of the CCGT and OCGT during a frequency increase event. 
Following the load reduction event system frequency increases at a higher rate when the OCGT in place compared to the CCGT scenario due to the low inertia of the OCGT unit. Therefore, the OCGT governor indicates a much steeper response compared to that for the CCGT during the first few seconds of the load reduction event due to the slightly larger rate of change of frequency for the OCGT scenario. It should be noted that system frequency recovers to nominal system frequency at a slower rate as the frequency droop is employed at both G1 (i.e. either CCGT for OCGT) and external grid. Ultimately, due to the governor response fuel demand is reduced (from $1 \mathrm{pu}$ t0 $0.70 \mathrm{pu}$ ), and ultimately it will lead to large reduction in turbine power output. According to Figure 10, both the CCGT and OCGT indicated a 24\% reduction in turbine power output (i.e. 96 MW). However, during this event temperature control loop doesn't override the governor response, although CCGTs are equipped with IGVs. Therefore, both the CCGT and OCGT have indicated same turbine power output reduction.

As the system frequency increases the air compressor speeds up, which leads to more air being drawn into the combustion chamber. This results in a low fuel-to-air ratio and consequently the turbine exhaust gas temperature reduces. For OCGTs the exhaust temperature spread is high compared to CCGTs (e.g. OCGT $-110^{\circ} \mathrm{F}, \mathrm{CCGT}-31^{\circ} \mathrm{F}$ ), since the latter is equipped with variable IGVs and so can reduce the air flow by 'closing' them (closing them from $1 \mathrm{pu}$ to $0.38 \mathrm{pu}$ ) when the turbine exhaust temperature falls in order to correct the exhaust temperature back to its optimal value (see Figure 11).

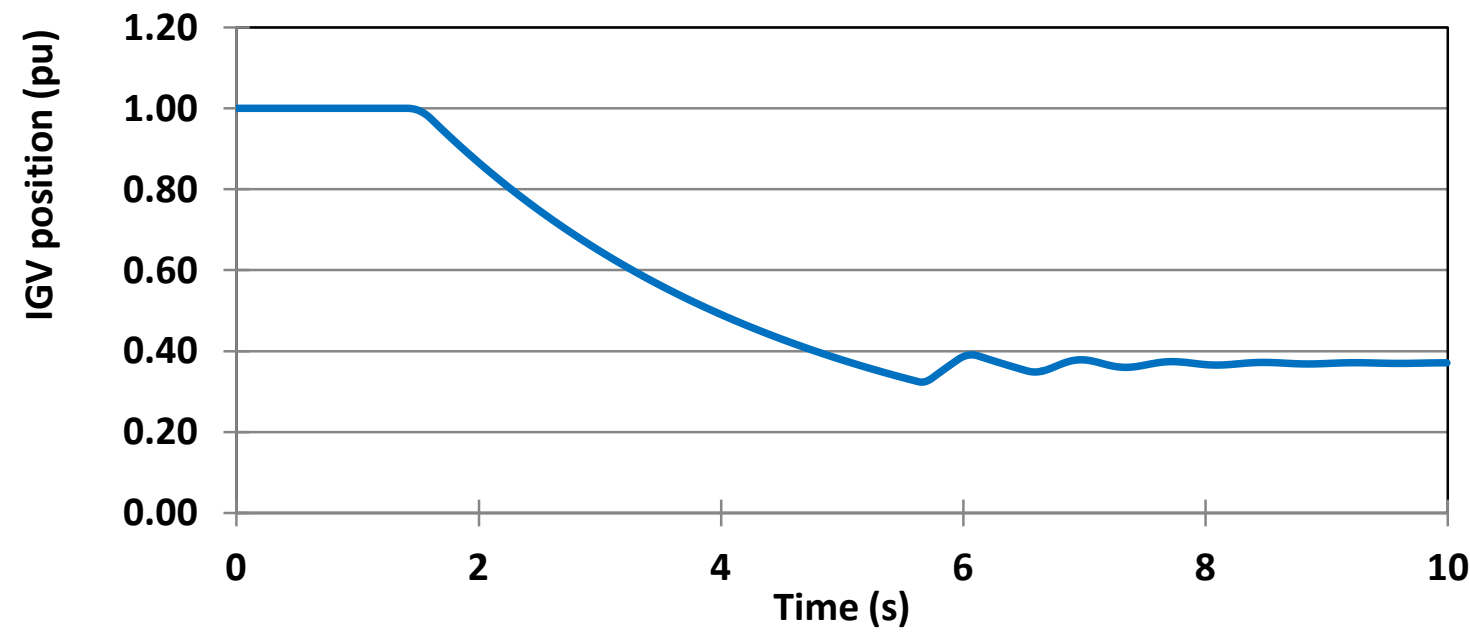

Figure 11: The IGV response during frequency increase event. 
However, OCGTs don't have IGVs to correct the exhaust temperature; hence its exhaust gas temperature decreases. When both gas turbines are operated below rated power output same trend can be observed. Therefore, CCGTs indicate much robust exhaust temperature compared to OCGTs during frequency increase events in the network due to the air flow control action performed by IGVs. Although, OCGTs indicate larger exhaust temperature spread, overall trend is a decrease, and also it is within the safe limits, hence it's very unlikely lead to a LBO condition during a 200 MW load reduction. In terms of the CCGT, exhaust gases indicate much larger temperature oscillations due to the continuous temperature control action performed by IGVs (see Figure 11).

Therefore, if a large load reduction event is taking place in the network that may lead to a large ROCOF, and ultimately that may lead to higher exhaust temperature spread, hence it's more likely lead to a LBO condition. This is because change in fuel flow is instantaneous; however due to the inertia of the rotating mass of the gas turbine, it pumps more air at a higher rate while reducing the fuel-to-air ratio below the lean flammability limit [15]. The turbine power output reduction during frequency increase events for various generator loading conditions are illustrated in Table 1. It should be noted that once the generator loading is reduced that additional load will be provided by the system equivalent (see Figure 7) while maintaining the same load in the network (i.e. $2000 \mathrm{MW}$ ) prior to the event, hence the system equivalent becomes more dominant in determining the initial frequency increase in the network when generator loading approaches $50 \%$. For the each generator loading scenario shown in Table 1, a $200 \mathrm{MW}$ load was disconnected from the test system and turbine power decrease is calculated as a percentage of steady-state power output prior to the frequency increase event during the tests carried out for various generator loading levels. 
Table 1: Gas turbine power output decrease for different generator loading levels during a frequency increase event

\begin{tabular}{c|c|c|c|c}
\hline \hline \multirow{2}{*}{$\begin{array}{c}\text { Generator } \\
\text { Loading }\end{array}$} & \multicolumn{2}{|c|}{ OCGT } & \multicolumn{2}{c}{ CCGT } \\
\cline { 2 - 5 } & $\begin{array}{c}\text { Turbine power } \\
\text { reduction }\end{array}$ & $\begin{array}{c}\text { Frequency } \\
\text { increase }\end{array}$ & $\begin{array}{c}\text { Turbine power } \\
\text { reduction }\end{array}$ & $\begin{array}{c}\text { Frequency } \\
\text { increase }\end{array}$ \\
\hline $100 \%$ & $35.80 \%$ & $0.75 \mathrm{~Hz}$ & $34.32 \%$ & $0.70 \mathrm{~Hz}$ \\
\hline $90 \%$ & $40.11 \%$ & $0.75 \mathrm{~Hz}$ & $38.42 \%$ & $0.70 \mathrm{~Hz}$ \\
\hline $80 \%$ & $45.33 \%$ & $0.75 \mathrm{~Hz}$ & $43.51 \%$ & $0.70 \mathrm{~Hz}$ \\
\hline $70 \%$ & $52.03 \%$ & $0.75 \mathrm{~Hz}$ & $50.14 \%$ & $0.71 \mathrm{~Hz}$ \\
\hline $60 \%$ & $60.95 \%$ & $0.76 \mathrm{~Hz}$ & $58.97 \%$ & $0.71 \mathrm{~Hz}$ \\
\hline $50 \%$ & $61.96 \%$ & $0.78 \mathrm{~Hz}$ & $61.92 \%$ & $0.78 \mathrm{~Hz}$ \\
\hline \hline
\end{tabular}

According to Table 1, the OCGT experiences a slightly high power reduction in comparison to the CCGT. This is due to the fact that the OCGT experiences a much higher frequency increase than the CCGT due to the low inertia of the OCGT (hence low inertial response) in comparison to the CCGT. Therefore, the OCGT speed governor response (i.e. fuel reduction command) is much larger than the CCGT governor response; hence OCGT has resulted in much larger turbine power output decrease in comparison to CCGT.

When generator power output decreases both gas turbines have resulted in an increase in the active power reduction. This is due to the fact that governor signal for fuel reduction becomes more dominant (since system frequency increase for all loading scenarios is almost same), over the steady-state fuel requirement. Therefore, when power output decreases, impact of governor response is much larger than it operates at the rated power output, hence greater turbine power output reduction can be perceived when gas turbines are operating at partial load. 


\subsection{Dynamic behaviour of Gas Turbines during Short-Circuit Events}

During short-circuit events generators are subjected to large electro-mechanical oscillations due to the large voltage drop across a wide-area of the power network. Therefore, during short-circuit faults large frequency excursions and ROCOFs can be observed. Figure 12 illustrates the dynamic behaviour of the CCGT and OCGT units during a $150 \mathrm{~ms}$ short-circuit fault in the test system. It is assumed that both units are operating at rated power output.
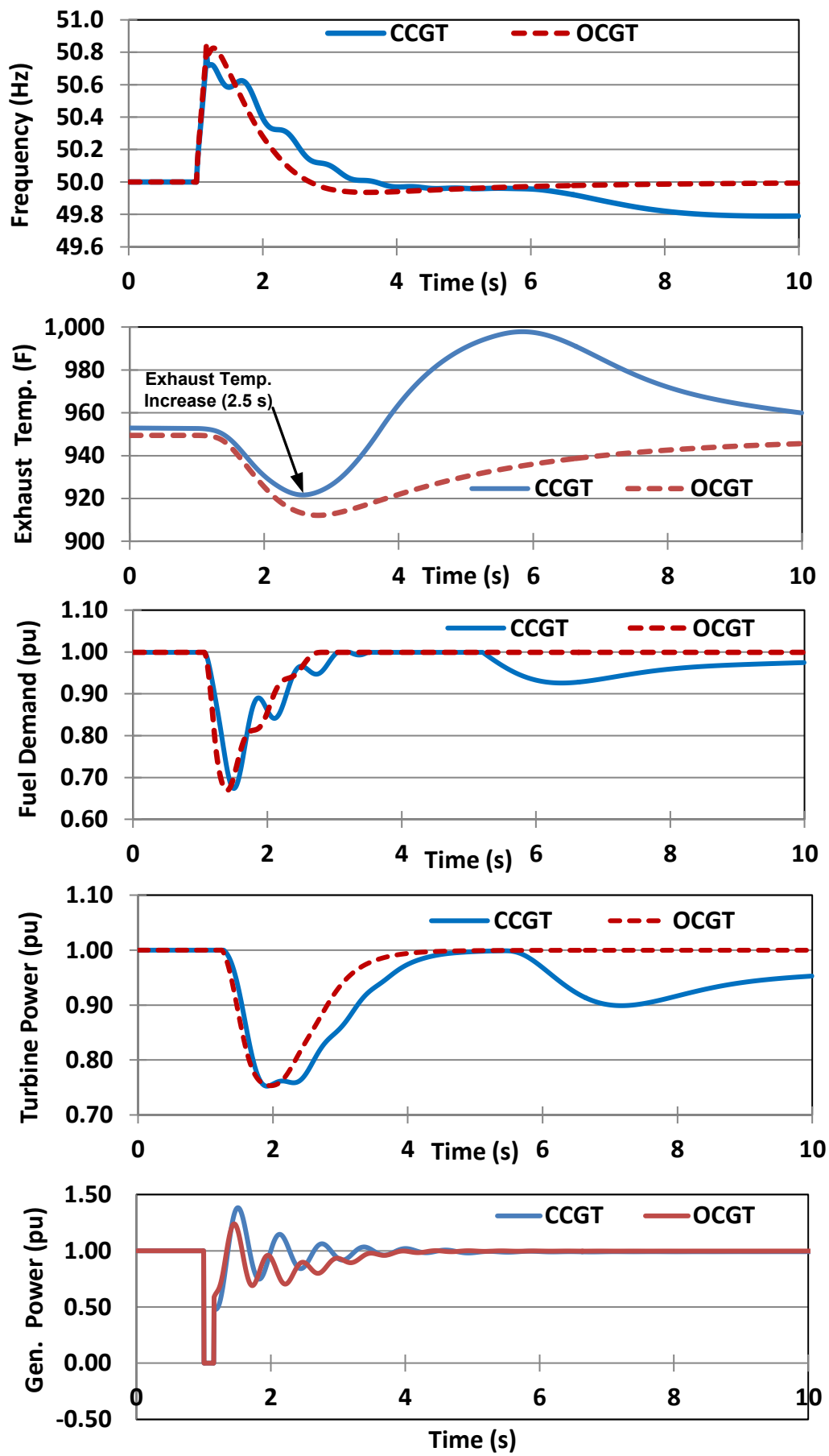

Figure 12: Dynamic behaviour of the gas turbine units during a short-circuit fault. 
According to Figure 12 system frequency has significantly increased during the fault for both scenarios (i.e. CCGT and OCGT). In particular, the OCGT has indicated a significantly large frequency increase compared to the CCGT. For the OCGT scenario it has indicated a ROCOF of $0.89 \mathrm{~Hz} / \mathrm{s}$ while the corresponding value for the CCGT was $0.71 \mathrm{~Hz} / \mathrm{s}$. This has resulted in a substantial reduction in fuel inflow to the combustion chamber, and the accelerated compressor pumps more air to the combustor, and ultimately turbine power output has decreased substantially. However, the turbine power output reduction (i.e. 25\%) is almost similar for both the CCGT and OCGT, although the OCGT experiences a much higher ROCOF during the fault in the network. This is due to the fact that fuel demand reduction for both the CCGT and OCGT is almost similar.

After fault clearance, system frequency recovers to nominal system frequency at a steeper rate while demanding more fuel being injected to the combustion chamber, however now the CCGT IGVs are at their minimum value, and the compressor also slows down while reducing the air-flow to the combustion chamber. This substantial air-flow reduction at the CCGT has subsequently reduced the air-to-fuel ratio while resulting a steep increase in the exhaust gas temperature $(t=2.5 \mathrm{~s})$. In this particular scenario the exhaust temperature spread for the CCGT is around $66^{\circ} \mathrm{F}$ which is below the LBO exhaust temperature spread [20], however characteristic exhaust temperature behaviour during a LBO event can be observed at the CCGT during this fault. In terms of the OCGT, it has indicated an exhaust temperature spread of $38^{\circ} \mathrm{F}$. The CCGT illustrates more detrimental exhaust temperature characteristics due to the airflow control action of the IGVs during the fault (see Figure 13). Therefore, CCGTs are much more susceptible to the LBO during short-circuit faults in the network. 


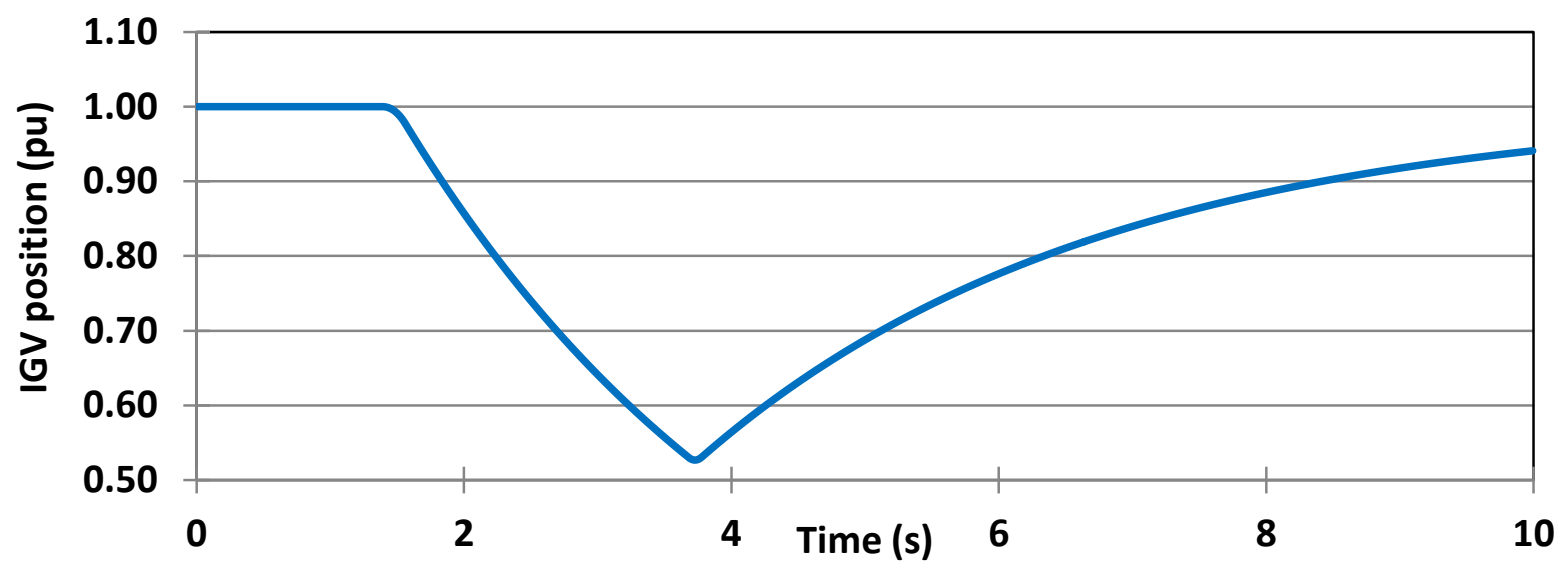

Figure 13: Variation of the CCGT IGV position during the fault.

At $\mathrm{t}=5.4 \mathrm{~s}$ due to the exhaust temperature increase, temperature control system starts to override the governor signal, and ultimately fuel system starts to reduce the fuel flow to the combustion chamber (see Figure 14). This has resulted in a decrease in turbine power output and ultimately frequency decrease further $(t=6.3 \mathrm{~s})$.

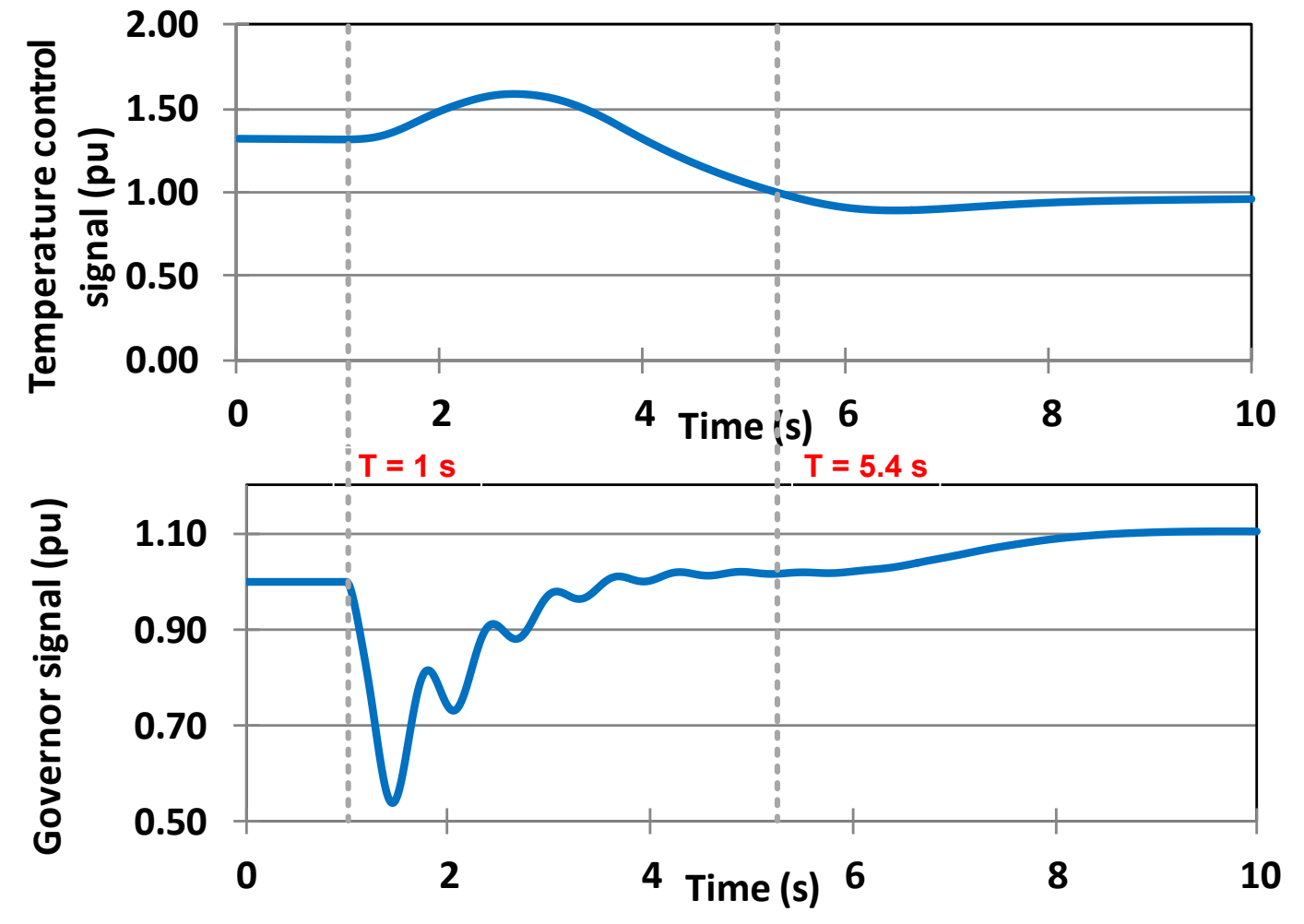

Figure 14: Temperature control and governor control signal at the CCGT.

During fault conditions CCGTs are more susceptible to the LBO condition due to the IGV temperature control action. In order to further investigate this issue, fault duration has been increased until both the CCGT and OCGT reaches to their LBO exhaust temperature spread. It has indicated that $530 \mathrm{~ms}$ fault can lead the CCGT to LBO, and 
the resulting ROCOF during that fault was $2.28 \mathrm{~Hz} / \mathrm{s}$. In terms of the $90 \%$ loading the exhaust temperature spread has reached the LBO limit when the fault persists for $980 \mathrm{~ms}$, and the resulting ROCOF was $3.87 \mathrm{~Hz} / \mathrm{s}$. In terms of OCGTs, a fault should persist for $1.6 \mathrm{~s}$ in order to lead to LBO when they operate at the rated power output. Therefore, it can be concluded that CCGTs are more susceptible to the LBO during shortcircuit faults whet they operate at rated power output. 


\section{A Case Study}

A case study was developed using the New England-39 bus test system, in order to assess the dynamic impact of gas turbines during short-circuit faults in power networks, as it is the most detrimental condition for generators as discussed in Section 4.3. The generators are adopted with three different plant models (i.e. CCGT, OCGT and steamturbine (ST)), and the governor droop was set at 4\%. The generator exciters were represented by the standard IEEE models [17, 21]. A schematic of the test system is illustrated in Figure 15, and the generation portfolio for each region as a percentage of total generation in the region is given in Table 2 .

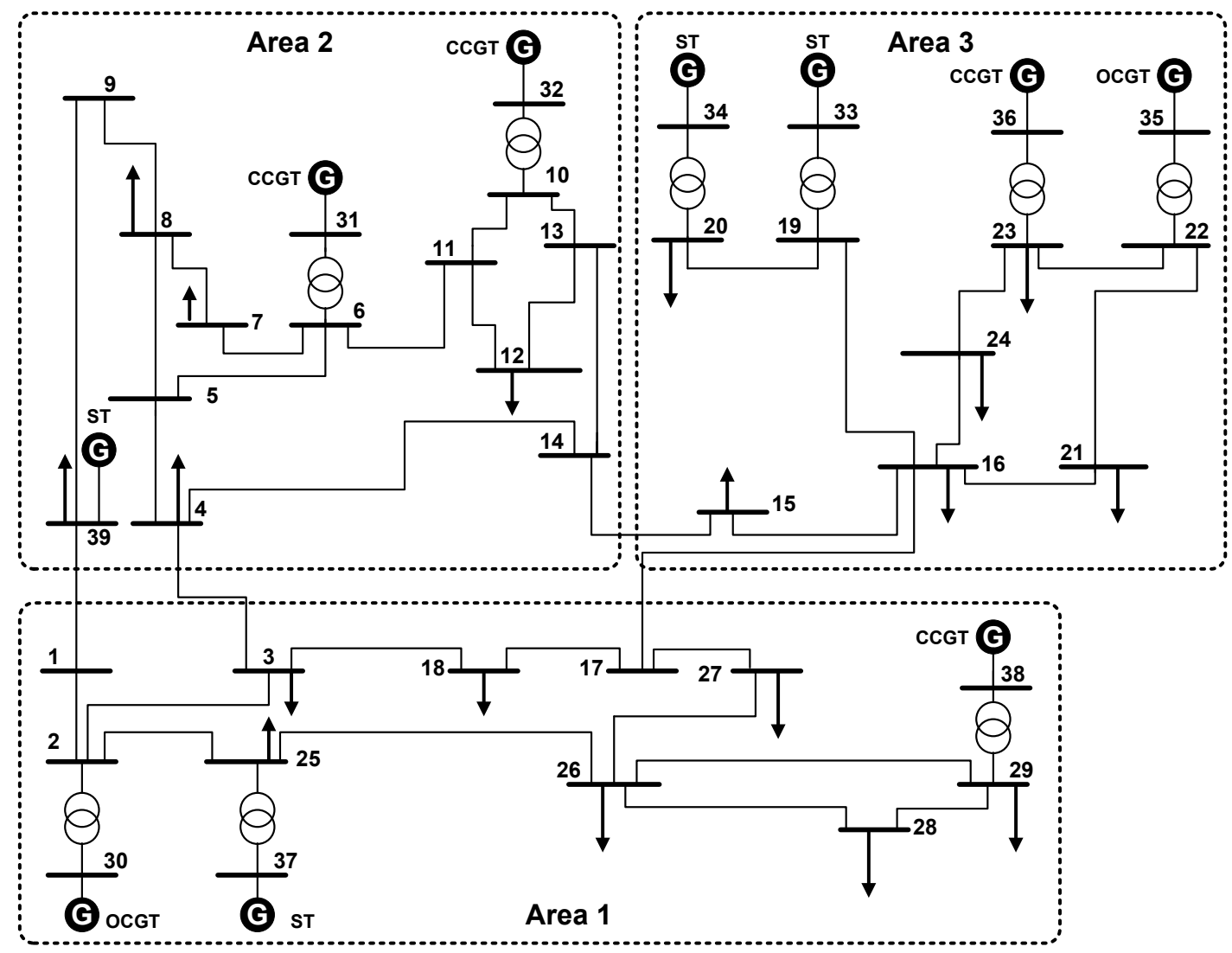

Figure 15: A schematic of the New England-39 bus system.

Table 2: Generation portfolio for each area of the New England-39 bus system

\begin{tabular}{c|c|c|c|c}
\hline \hline Area & ST & OCGT & CCGT & $\begin{array}{c}\text { Average inertia } \\
\text { constant }\end{array}$ \\
\hline 1 & $33.33 \%$ & $15.43 \%$ & $51.23 \%$ & $7.55 \mathrm{~s}$ \\
\hline 2 & $45.25 \%$ & $0.00 \%$ & $54.75 \%$ & $6.94 \mathrm{~s}$ \\
\hline 3 & $48.51 \%$ & $27.66 \%$ & $23.83 \%$ & $5.71 \mathrm{~s}$ \\
\hline \hline
\end{tabular}


According to Table 2, Area 1 has the highest inertia while the Area 3 has the lowest inertia in the New England-39 bus system. This is due to the fact that majority of the generation in Area 1 is comprised of CCGTs with a high inertia constant, and in Area 3 CCGT penetration is low.

A $250 \mathrm{~ms}$ short-circuit fault was initiated in each generation region in the New England-39 bus system, and observed the frequency and exhaust temperature variation. Figure 16 illustrates the frequency variation for each region under different fault scenarios.
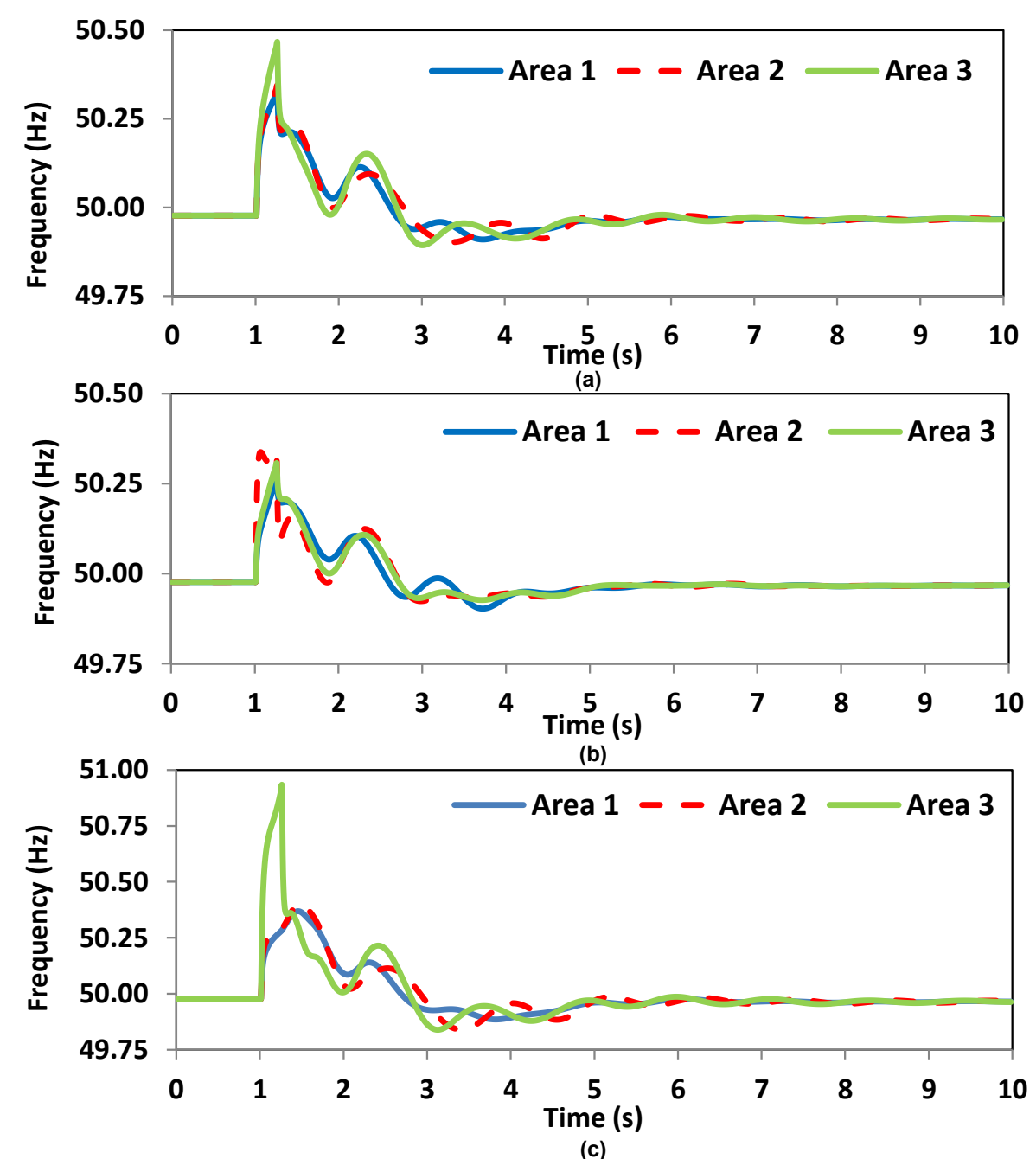

Figure 16: Frequency variation for each region; (a) Fault in area 1, (b) Fault in area 2, (c) Fault in area 3.

According to Figure 16, Area 3 has indicated the highest and lowest frequency when a fault occurs in Areas 1 and 3. This is due to the fact that Area 3 has the least inertia among all the other regions in the New England 39 bus system; hence generators 
accelerate at a higher rate during the fault while resulting a large frequency increase in the region. Therefore, a good correlation can be observed between regional frequency variations and inertia of each region (see Table 3).

Table 3: Minimum and maximum frequencies of each region during short-circuit faults

\begin{tabular}{c|c|c|c|c|c|c}
\hline \multirow{2}{*}{ Fault Area } & \multicolumn{2}{|c|}{ Area 1 } & \multicolumn{2}{c|}{ Area 2 } & \multicolumn{2}{c}{ Area 3 } \\
\cline { 2 - 7 } & $\begin{array}{c}\text { Min. } \\
\text { Frequency }\end{array}$ & $\begin{array}{c}\text { Max. } \\
\text { Frequency }\end{array}$ & $\begin{array}{c}\text { Min. } \\
\text { Frequency }\end{array}$ & $\begin{array}{c}\text { Max. } \\
\text { Frequency }\end{array}$ & $\begin{array}{c}\text { Min. } \\
\text { Frequency }\end{array}$ & $\begin{array}{c}\text { Max. } \\
\text { Frequency }\end{array}$ \\
\hline 1 & $49.91 \mathrm{~Hz}$ & $50.33 \mathrm{~Hz}$ & $49.90 \mathrm{~Hz}$ & $50.26 \mathrm{~Hz}$ & $49.89 \mathrm{~Hz}$ & $50.37 \mathrm{~Hz}$ \\
\hline 2 & $49.90 \mathrm{~Hz}$ & $50.34 \mathrm{~Hz}$ & $49.92 \mathrm{~Hz}$ & $50.34 \mathrm{~Hz}$ & $49.84 \mathrm{~Hz}$ & $50.40 \mathrm{~Hz}$ \\
\hline 3 & $49.89 \mathrm{~Hz}$ & $50.47 \mathrm{~Hz}$ & $49.93 \mathrm{~Hz}$ & $50.31 \mathrm{~Hz}$ & $49.84 \mathrm{~Hz}$ & $50.93 \mathrm{~Hz}$ \\
\hline \hline
\end{tabular}

As these frequency variations also affect the governor response it is imperative to analyse the turbine response in each region. Figure 17 illustrates the turbine response of Area 2 and Area 3 for a 250 three-phase short-circuit fault in Area 2.

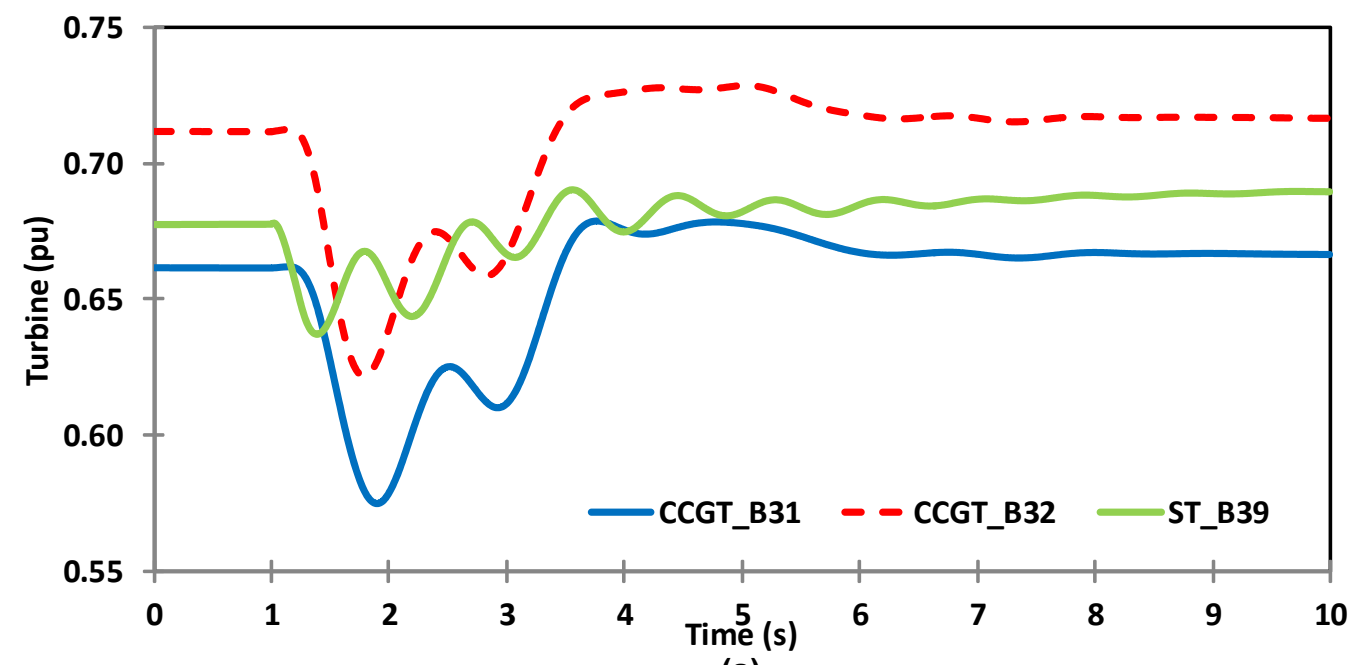

(a)

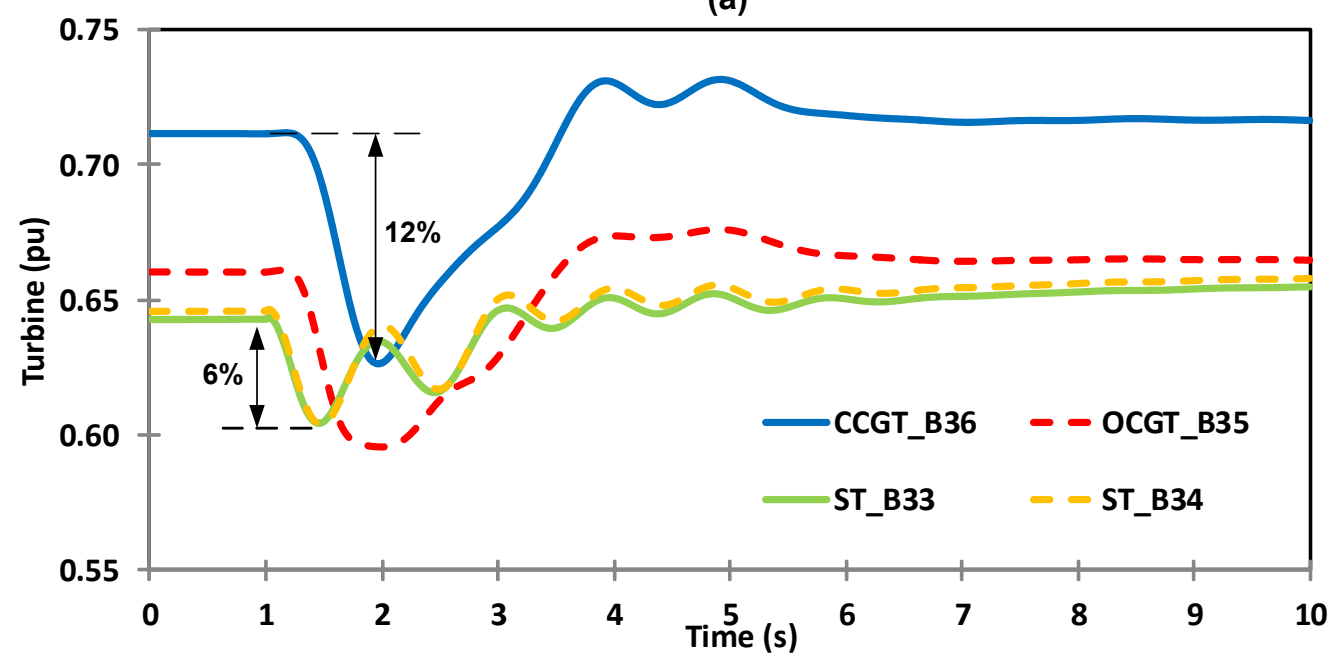

(b)

Figure 17: Turbine response during a short-circuit event in Area 2; (a) Area 2, (b) Area 3. 
According to Figure 17, CCGTs and OCGTs are severely affected during the fault in comparison to the steam turbine (ST) units. For example, during the fault in Area 2, the CCGT at bus 36 has indicated a turbine power output reduction of $12 \%$ while the ST unit installed at bus 33 has indicated only a $6 \%$ power output reduction. This is due to the aforementioned fact (in Section 4.3) that as the frequency increases, in order to correct the exhaust temperature, the temperature control system overrides the governor signal, and ultimately it further reduces the fuel flow to the combustion chamber while resulting a power output reduction at the CCGT. Therefore, such a significant turbine power output decrease may trigger frequency stability issues in the network.

Furthermore, as Area 3 indicates the highest frequency increase during two fault scenarios (see Figure 16); it may detrimentally affect the gas turbines installed in the region. In particular, it may affect the gas turbine exhaust temperature while triggering the LBO condition. Figure 18 illustrates the exhaust temperature variation of the CCGT installed at bus 36 for short-circuit faults in each region.

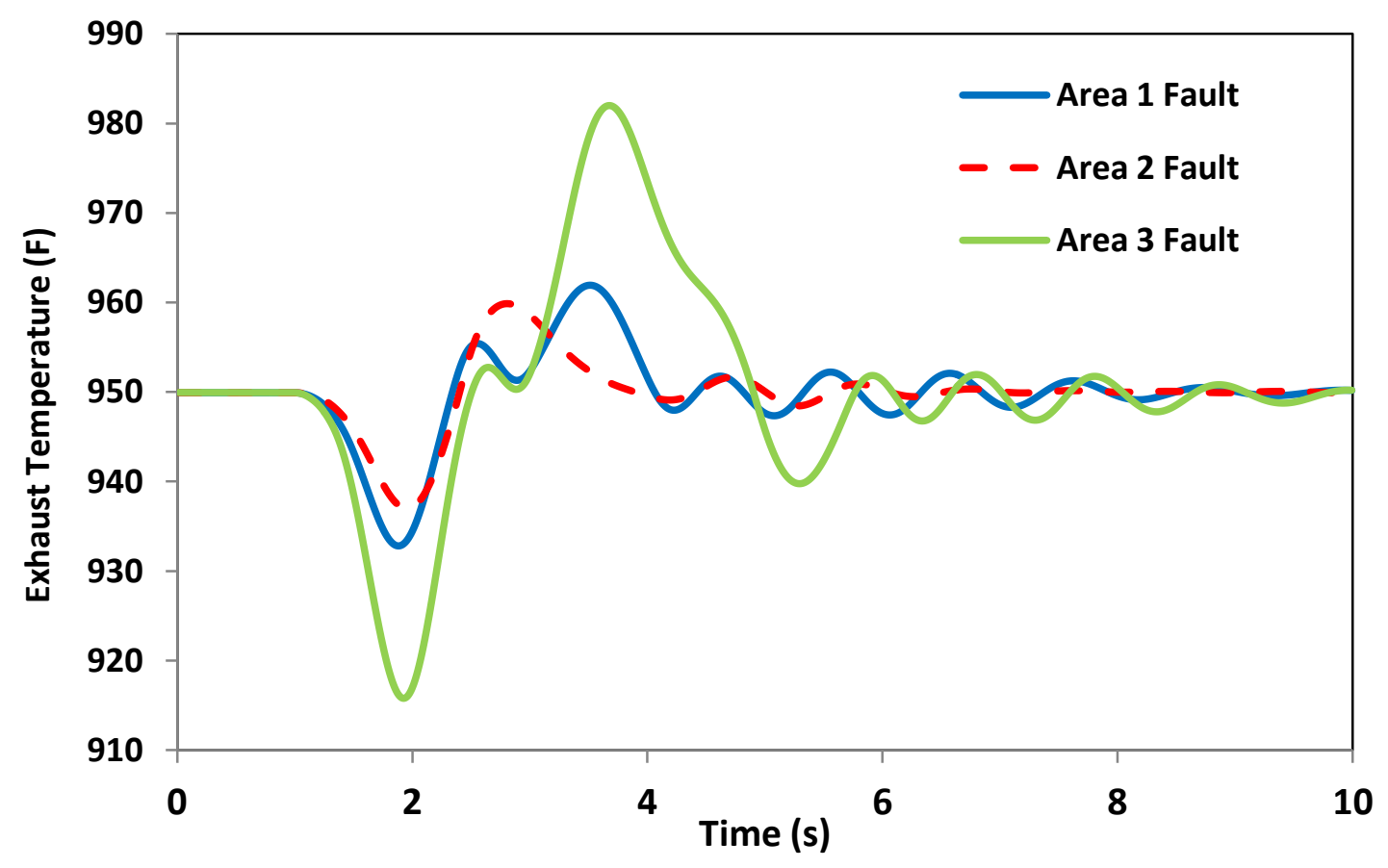

Figure 18: Exhaust temperature variation for the CCGT at bus 36.

According to Figure 18, the exhaust temperature variation can be directly correlated to the frequency variation in Area 3. For example, fault at Area 3 has resulted in the highest rate of change of frequency, and ultimately the CCGT at bus 36 has indicated an exhaust 
temperature variation of $66.22^{\circ} \mathrm{F}$ which is $37.13{ }^{\circ} \mathrm{F}$ higher than the other fault scenarios. Therefore, the CCGT at bus 36 is more susceptible to LBO condition than the other CCGTs operating in the network.

\section{Conclusions}

This study has characterised the dynamic behaviour of the CCGT and OCGT units during different frequency events in power networks. The study has shown that the temperature control system associated with the CCGT may lead to turbine power output reduction during both frequency increase and decrease events, which may be detrimental to frequency stability of the network. In particular, when CCGTs operate at rated power output the turbine power output reduction can be severe enough to cause frequency stability issues in power networks. However, when CCGTs operate below rated power output, the dynamic characteristics are comparable to the OCGT. Furthermore, gas turbine dynamics during frequency transients due to short-circuit events have been investigated with particular emphasis on lean blowout (LBO) condition, and outcome of the investigation was further confirmed by a case study developed based on the New England-39 bus system. It has shown that CCGTs are more susceptible to LBO condition due to the large rate-of-change-of-frequency (ROCOF) resulting from short-circuit events, in particular in regions with lower inertia. 


\section{Appendices}

\section{Appendix A: CCGT and OCGT dynamic simulation model parameters $[2,10]$}

Note: All symbols are given according to the standard symbols used in the dynamic simulation model illustrated in Figures 1 and 2.

Fuel control delay time $\left(T_{f d}\right)=0.0625 \mathrm{~s}$; Fuel system delay $\left(T_{f}\right)=0.4 \mathrm{~s}$; Turbine time delay $\left(T_{c}\right)=0.1 \mathrm{~s} ;$ Speed governor gain $\left(K_{d r p}\right)=25 ;$ Speed governor time constant $\left(T_{d r p}\right)=0.05 \mathrm{~s} ;$ Temperature controller time constant $\left(T_{t}\right)=450 \mathrm{~s}$; Turbine exhaust transport delay $\left(E_{t d}\right)=$ $0.01 \mathrm{~s}$; Rated exhaust temperature $\left(T_{c}\right)=950^{\circ} \mathrm{F}$; IGV actuator time constant $\left(T_{i}\right)=3 \mathrm{~s}$; IGV controller time constant $\left(T_{d}\right)=20 \mathrm{~s}$; IGV controller gain $\left(K_{i}\right)=4$; Fuel system delay $\left(E_{c r}\right)=0.01 \mathrm{~s} ;$ Minimum fuel limit $\left(f l \_\min \right)=0.15 ;$ Maximum fuel limit $\left(f l \_\max \right)=0.7692 ;$ IGV min limit $\left(i g v_{-} \min \right)=0.095 ; \operatorname{IGV} \max$ Limit $\left(i g v_{-} \max \right)=1.0 ; \operatorname{Max}=7.3$.

\section{Appendix B: IEEE Type 1 Excitation System Models [17]}

Regular Measurement Delay $\left(T_{r}\right)=0.028 \mathrm{~s}$; Amplifier Gain $\left(K_{a}\right)=175$; Amplifier Time Constant $\left(T_{a}\right)=0.03 \mathrm{~s}$; Controller Output Maximum $\left(V R_{\max }\right)=12$; Controller Output Minimum $\left(V R_{\min }\right)=-12$; Exciter Time Constant $\left(T_{e}\right)=0.266 \mathrm{~s} ;$ Feedback Path Gain $\left(K_{g}\right)=$ 0.0025; Feedback Path Time Constant $\left(T_{g}\right)=1.5 \mathrm{~s}$. 


\section{References}

[1] Fox, B., Flynn, D., Bryans, L., Jenkins, N., Milborrow, D., O' Malley, M., Watson, R.: 'Wind Power Integration: Connection and System Operation Aspects' (IET London U.K., 2007).

[2] Rowen, W.I.: 'Simplified mathematical representations of heavy-duty gas turbines', J. Eng. Power, 1983, 105, (1), pp. 865-869.

[3] IEEE Working Group on Prime Mover and Energy Supply Models for System Dynamic Performance Studies: 'Dynamic models for combined cycle plants in power system studies', IEEE Trans. Power Syst., 1994, 9, (3), pp. 1698-1708.

[4] Kunitomi, K., Kurita, A., Okamoto, H., Tada, Y., Ihara, S., Pourbeik, P., Price, W.W., Leirbukt, A.B., Sanchez-Gasca, J.J.: 'Modeling frequency dependency of gas turbine output', In Proc: IEEE Power Eng. Soc. Winter Meeting, Columbus, USA, 2001.

[5] Kunitomi, K., Kurita, A., Tada, Y., Ihara, S., Price, W.W., Richardson, L.M., Smith, G.: 'Modeling combined-cycle power plant for simulation of frequency excursions', IEEE Trans. Power Syst., 2003, 18, (2), pp. 724- 729.

[6] CIGRE Task Force: 'Modeling of gas turbines and steam turbines in combined cycle power plants', 2003.

[7] Soon, K.Y., Milanovic, J.V., Hughes, F.M.: 'Overview and comparative analysis of gas turbine models for system stability studies', IEEE Trans. Power Syst., 2008, 23, (1), pp. 108-118.

[8] Hannett, L.N., Khan, A.H.: 'Combustion turbine dynamic model validation from tests', IEEE Trans. Power Syst., 1993, 8, (1), pp. 152-158.

[9] Tavakoli, M.R.B., Vahidi, B., Gawlik, W.: 'An educational guide to extract the parameters of heavy duty gas turbines model in dynamic studies based on operational data', IEEE Trans. Power Syst., 2009, 24, (3), pp. 1366 - 1374.

[10]Lalor, G., Ritchie, J., Flynn, D., O'Malley, M.J.: 'The impact of combined-cycle gas turbine short-term dynamics on frequency control', IEEE Trans. Power Syst., 2005, 20, (3), pp. 14561464.

[11]Bagnasco, A., Delfino, B., Denegri, G.B., Massucco, S.: 'Management and dynamic performances of combined cycle power plants during parallel and islanding operation', IEEE Trans. Energy Conv., 1998, 13, (2), pp. $194-201$.

[12] Kakimoto, N., Baba, K.: 'Performance of gas turbine-based plants during frequency drops', IEEE Trans. Power Syst., 2003, 18, (3), pp. 1110- 1115.

[13] Doyle, J.: 'Grid requirements on CCGT plants', CIGRE, Ireland, . 
[14] Meegahapola, L., Flynn, D.: 'Frequency dynamics during high CCGT and wind penetrations', $21^{\text {st }}$ Australasian Universities Power Engineering Conference (AUPEC), Brisbane, Australia, 2011.

[15] NERC Industry Advisory: 'Turbine combustor lean blowout', Jun. 2008.

[16] FRCC: 'FRCC system disturbance and underfrequency load shedding event report', 2008.

[17]IEEE Committee Report: 'Computer representation of excitation systems', IEEE Trans. on Power Apparatus and Syst., 1968, 87, (3), pp. 1460-1464.

[18] System Operator Northern Ireland: 'Minimum fucntion specification for centrally disptached OCGT units', 2008.

[19] System Operator Northern Ireland: 'Minimum fucntion specification for centrally disptached CCGT units', 2010.

[20] PAL Turbine Services: 'Turbine Tips: Root Causes of High Exhaust Temperature Spreads', http://www.pondlucier.com/Company/tip.htm, accessed May 2013.

[21] IEEE Standard 421.5-2005: 'IEEE Recommended Practice for Excitation System Models for Power System Stability Studies', 2006. 